\title{
Finite lifetimes and government spending in an endogenous growth model
}

\author{
Stephen Kosempel \\ Department of Economics and Finance, University of Guelph \\ kosempel@uoguelph.ca
}
Department of Economics and Finance University of Guelph Discussion Paper 2003-13

Accepted Manuscript @ Journal of Economics and Business

(C) 2004, Elsevier. Licensed under the Creative Commons Attribution-Non CommercialNo Derivatives 4.0 International http://creativecommons.org/licenses/by-nc-nd/4.0/

The final publication of this article is available at www.elsevier.com

DOI: http://dx.doi.org/10.1016/j.jeconbus.2003.08.002 


\title{
Finite lifetimes and government spending in an
}

\section{endogenous growth model}

\author{
Stephen Kosempel* \\ University of Guelph, Department of Economics and Finance, \\ Guelph, Ontario, N1G 2W1, Canada
}

\begin{abstract}
This paper studies the long-run effects of government spending and taxation in an endogenous growth model with finite lived agents. Public expenditures are classified according to their type: Type I expenditures enter as inputs into the production function. Type II expenditures enter as goods into the utility function. Mourmouras and Lee (1999) demonstrated that when only Type I expenditures are incorporated into the analysis, the tax rate that maximizes the welfare of the average agent is invariant to life expectancy. It will be demonstrated that their result no longer holds when their framework is extended to incorporate Type II expenditures.
\end{abstract}

JEL classification: E62; H54; O41

Keywords: Endogenous growth; government spending; finite horizons

*Tel: (519) 824-4120 Ext. 56339; Fax: (519) 763-8497; Email: kosempel@uoguelph.ca 


\section{Introduction}

The empirical growth literature has found life expectancy to have a positive and statistically significant impact on economic growth [for instance, Barro and Sala-i-Martin (1995), Barro (1997) and Bhargava et al. (2001)]. The results of Barro and Sala-i-Martin (1995, pp. 432) suggest that an increase in life expectancy of 13 years would increase a country's growth rate by 1.4 percentage points per year. Barro (1997) has also found life expectancy to have a positive and statistically significant impact on the investment rate. Several explanations have been suggested to account for the strong positive relationships observed between life expectancy and economic performance. First, life expectancy has been used as a proxy for health status, and better health has been linked to economic productivity [see Bhargava et al. (2001) for a review of the micro studies that show the benefits of better health on productivity]. Second, Kalemli-Ozcan et al. (2000) have examined the role of increased life expectancy in raising human capital investment during the

process of economic growth. Finally, Blanchard (1985) has demonstrated that life expectancy affects consumption and savings decisions, and therefore transitional growth. In the current paper an alternative theory is provided to help explain the positive effect that life expectancy has on economic performance. Specifically, it will be demonstrated that when life expectancy is short, the government will favour high tax/slow growth policies.

This study builds primarily on the theoretical models of Barro (1990), Mourmouras and Lee (1999) and Blanchard (1985). Barro (1990) developed a 
model in which government services affect the long-run performance of an economy by entering as an input, along with private capital, into the production function for final output. Here we can think of the public provision of infrastructure such as roads, airports, harbors and sewer systems; or public expenditures on law and order, education and R\&D. Barro's main theoretical prediction is that increases in government expenditures on infrastructure are associated with higher long-run growth rates; however, this rise in growth rates is reversed after a point (the hump-shaped Barro curve), showing that there is an optimum value for public investment. Mourmouras and Lee (1999) extended Barro's results by relaxing his assumption that agents have infinite lifetimes. More specifically, Mourmouras and Lee combined the Barro (1990) endogenous growth model with the Blanchard (1985) overlapping generations model. Like Barro, government spending enters as an input into their production function; and like Blanchard, their model is populated by consumers with uncertain lifetimes. Within this framework Mourmouras and Lee demonstrated that the income tax rate that maximizes social welfare and economic growth is invariant to the life expectancy of the agents in the economy.

The current paper contributes to the literature that links government activities to growth by demonstrating that the Mourmouras and Lee result, pertaining to optimal taxation, is sensitive to their assumption that government tax revenue is used only to finance public infrastructure. An alternative assumption, and one that is more realistic, is that government 
revenue may also be used to finance services that enter as a good directly into the utility function. Here we can think of the public provision of social programs, health care, museums, art galleries and parks. It will be demonstrated that when households receive utility from government services directly, the tax and expenditure policy that maximizes welfare depends on life expectancy, and differs from the policy that maximizes economic growth. In the model, when life expectancy is short, the government is less forward looking, in the sense that the optimal policy leads to slow growth.

The literature that links government activity to economic growth extends well beyond the few papers mentioned above. A description of some of the more relevant papers will be provided in the remainder of this section. For example, Rebelo (1991) studied the effects of government taxation on the growth process using an infinite horizon endogenous growth model. However, in his model he assumed that government spending is completely wasteful; that is, it enters neither the utility function nor the production function. Reinhart (1999) extended Rebelo's analysis by assuming that agents have finite lifetimes; however, like Rebelo he assumed no role for government spending. The idea that part of government spending is utility enhancing and part is productivity enhancing within an endogenous growth framework is by no means new. Barro (1990), Turnovsky and Fisher (1995), Turnovsky (1996), and Bruce and Turnovsky (1999); all included both types of government spending in their models, but they all assumed that agents live for infinite period. Ghosh and Mourmouras (2002) extended Barro's model to a two 
country environment with both types of government expenditures and finite lived agents, but they assumed lump-sum taxation and only considered the optimal provision of productive government services. In comparison, in the current paper, government revenue is funded via a proportional income tax and both types of government spending are determined endogenously. The main result of the paper is its finding that both the income tax rate and the optimal composition of government spending are sensitive to life expectancy.

The remainder of the paper is organized as follows: Section 2 provides a description of the theoretical model. Section 3 discusses the implications of the model for public policy. Section 4 provides some concluding remarks.

\section{The Model}

The artificial economy consists of three sectors: a household sector, a production sector and a government sector. The household sector is modeled by an overlapping generations framework developed by Blanchard (1985). The production sector is modeled by an endogenous growth framework developed by Barro (1990). An innovation in this paper is to expand the government sector and household preferences; by allowing government expenditures to consist of utility enhancing services, as well as productive services or infrastructure.

Productive government services are assumed to have the characteristics of a public good; that is, a unit of the service used by one firm does not preclude 
its use by other firms. Since the private provision of public goods is known to be inefficient, a role exists for government provision. Utility enhancing services, on the other hand, are assumed to be depletable. In other words, a unit of the service consumed by one household detracts from the amount remaining to be distributed to other households. Although utility enhancing services, such as health care, could be provided efficiently by the private sector; in the model and in many real economies these services are often provided by the public sector. The justification for this is that it allows the government to control their distribution.

\subsection{Households}

At any instant of time, a large cohort is born, whose size is normalized to $\lambda$. Each agent faces a constant probability of death per unit of time, which is also equal to $\lambda$. The probability that an agent born at time $i \leq t$ is alive at time $t$ is $e^{-\lambda(t-i)}$. The life expectancy for an agent of any age is $\int_{0}^{\infty} t \lambda e^{-\lambda t} d t=1 / \lambda$. As $\lambda$ goes to zero, $1 / \lambda$ goes to infinity, and we say that households have infinite horizons.

It is assumed that new generations are not connected to old generations, and therefore there is no bequest motive. Thus, households are born without financial assets. In the absence of bequests, households contract actuarially fair life insurance with annuities companies. A household with a wealth of $a$ will receive $\lambda a$ from an insurance company if its survives and pay $a$ if it dies.

The representative household of the cohort born at time $i$ receives utility 
at time $t$ by consuming a privately produced good, $c(i, t)$, and a service provided free by government, $x(i, t) .{ }^{1}$ The utility function of the representative household of cohort $i$ is given by:

$$
U(i, t)=\int_{t}^{\infty} u[c(i, v), x(i, v)] e^{-(\rho+\lambda)(v-t)} d v
$$

where

$$
u[c(i, v), x(i, v)]=\left\{\begin{array}{l}
\frac{(1-\beta) c(i, v)^{1-\sigma}+\beta x(i, v)^{1-\sigma}-1}{1-\sigma} \text { for } 0 \leq \sigma<1, \sigma>1 \\
(1-\beta) \ln c(i, v)+\beta \ln x(i, v) \text { for } \sigma=1 .
\end{array}\right\}
$$

Here $\rho$ is the pure rate of time preference and $\rho+\lambda$ is the effective discount rate. $^{2}$ The period utility function (2) takes the constant elasticity of substitution form, and has the property that the cross-partial derivatives are both zero. Since the marginal utility from the private consumption good does not depend on the amount of the government service that a household receives, a household's decision to consume or to save will be invariant to $x(i, t)$. This specification of preferences is convenient because it allows us to avoid generational issues; such as, should the government devote its services to the young or to the old members of society? Although studying the implications of these distributional concerns for productive potential and growth may represent an interesting area for future research, it is beyond the scope of the current analysis.

Denote $w(t)$ the age-independent real wage rate; $r(t)$ the real interest rate; and $a(i, t)$ the financial wealth of an agent born at time $i$, as of time $t$. The dynamic budget constraint is

$$
\frac{d a(i, t)}{d t}=[r(t)+\lambda] a(i, t)+w(t)-c(i, t) .
$$


Here $r(t) a(i, t)$ denotes the interest payment on the household's financial wealth and $\lambda a(i, t)$ is the premium received from the insurance company. In addition to the budget constrain, a transversality condition must be satisfied to prevent households from accumulating debt indefinitely:

$$
\lim _{v \rightarrow \infty}\left\{a(i, v) e^{-\int_{t}^{v}[r(u)+\lambda] d u}\right\}=0 .
$$

The representative household of cohort $i$ is endowed with perfect foresight and maximizes lifetime utility subject to its budget constraint and the transversality constraint. The optimization yields:

$$
\frac{d c(i, v)}{d v}=\sigma^{-1}[r(v)-\rho] c(i, v) .
$$

Integrating (3) and (5) and combining the results gives:

$$
c(i, t)=\frac{1}{\Delta(t)}[h(t)+a(i, t)]
$$

where

$$
\begin{aligned}
\Delta(t) & =\int_{t}^{\infty} \exp \left\{\frac{1}{\sigma} \int_{t}^{v}[(1-\sigma)[r(u)+\lambda]-(\lambda+\rho) d u]\right\} d v, \\
h(t) & =\int_{t}^{\infty} w(v) \exp \left\{-\int_{t}^{v}[r(u)+\lambda] d u\right\} d v .
\end{aligned}
$$

Here $\Delta(t)^{-1}$ is interpreted as the propensity to consume out of wealth, $h(t)$ is the present discounted sum of human wealth, and $h(t)+a(i, t)$ is total wealth. The propensity to consume is a function of the sequence of future interest rates, but is invariant to age, and therefore is the same for all agents.

Due to a constant probability of death, the size of a cohort declines deterministically through time. This is true despite the fact that individual 
households are uncertain about their time of death. A cohort born at time $i$ has a size as of time $t$ of $\lambda e^{-\lambda(t-i)}$. Following Blanchard (1985), the household sector can be aggregated by integrating over all currently alive generations.

For example, the size of the population at any time $t$ is $\int_{-\infty}^{t} \lambda e^{-\lambda(t-i)} d i=1$, and aggregate consumption is $\int_{-\infty}^{t} c(i, t) \lambda e^{-\lambda(t-i)} d i=C(t)$. Similarly, we can obtain the laws of motion for aggregate consumption, human wealth, $H(t)$, and non-human wealth, $A(t)$, by integrating equations (6), (8) and (3):

$$
\begin{aligned}
C(t) & =\Delta(t)^{-1}[H(t)+A(t)], \\
\dot{H}(t) & =[r(t)+\lambda] H(t)-W(t), \text { and } \\
\dot{A}(t) & =r(t) A(t)+W(t)-C(t) .
\end{aligned}
$$

Here $W(t)$ denotes aggregate labor income at time $t$, and a dot $(\cdot)$ over a variable indicates a time derivative. Differentiating (9) with respect to time and then substituting in for $\dot{H}(t)$ and $\dot{A}(t)$ gives

$$
\dot{C}(t)=\frac{1}{\sigma}[r(t)-\rho] C(t)-\Delta(t)^{-1} \lambda A(t) .
$$

A comparison of equations (5) and (12) indicate that individual and aggregate consumption grow at different rates. At the individual household level, consumption growth is financed in part by the transfer that households receive from the insurance companies. However, these transfers net out at the aggregate level, and therefore equation (12) deducts the propensity to consume out of the transfer from aggregate consumption growth. Heijdra and Ligthart (2002) used the term Generational Turnover Effect (GTE) to explain the differences in growth rates between the individual and aggregate variables in 
the Blanchard model. The GTE operates as follows: At each instant a new generation is born and a cross-section of the existing population dies. Since new born agents have no financial assets, their consumption is lower than average consumption. As a result, the turnover of generations drags down aggregate consumption growth.

\subsection{Production}

The production sector consists of a continuum of identical producers with locations of the interval $[0,1]$. Following Barro (1990), it is assumed that the government purchases a portion of private output and then uses these purchases to provide free public services to the private producers. The public services are assumed to be complementary to labor and private capital.

Productive government services, $G(t)$, labor, $L(t)$, and private capital, $K(t)$, enter as inputs into a Cobb-Douglas production function,

$$
Y(t)=F[G(t), K(t)]=B[G(t) \times L(t)]^{1-\alpha} K(t)^{\alpha},
$$

where $0<\alpha<1$ and $B$ is a constant. ${ }^{3}$ For a fixed $G$ and $L$ the economy faces diminishing returns to the accumulation of aggregate capital. However, since the production function specifies constant returns in $G$ and $K$ together; if $G$ rises with $K$, then diminishing returns will not set in. For this reason the economy is capable of endogenous growth. ${ }^{4,5}$

The representative firm's optimization problem is to choose an employment sequence and an investment sequence to maximize it's net present 
value,

$$
J(t)=\int_{0}^{\infty}[(1-\tau) Y(t)-\dot{K}(t)-\delta K(t)-w(t) L(t)] \times e^{-\int_{0}^{t} r(u) d u} d t
$$

where $\tau$ is a proportional tax applied to aggregate output. The first-order conditions equate the wage rate to the after-tax marginal product of labor and the interest rate to the after-tax rate of return to capital:

$$
\begin{aligned}
& w(t)=(1-\tau)(1-\alpha) B G(t)^{1-\alpha} L(t)^{-\alpha} K(t)^{\alpha}, \\
& r(t)=(1-\tau) \alpha B[G(t) \times L(t)]^{1-\alpha} K(t)^{\alpha-1}-\delta .
\end{aligned}
$$

\subsection{Government}

The government allocates a fraction, $\tau_{X} / \tau$, of its tax revenue to cover the costs of providing utility enhancing services to consumers; and a fraction, $\tau_{G} / \tau$, of its tax revenue to cover the costs of providing productive services to firms. Each period the government must satisfy the following constraints:

$$
\begin{aligned}
\tau & =\tau_{X}+\tau_{G}, \\
X(t) & =\tau_{X} Y(t), \\
G(t) & =\tau_{G} Y(t) .
\end{aligned}
$$

\subsection{Equilibrium}

In each time period there is a competitive equilibrium, which consists of an allocation $\{c(i, t), x(i, t), h(t), a(i, t)\}$ for all living households of each cohort $i \leq t$; an allocation $\{Y(t), L(t), K(t), G(t)\}$ for each firm; and a set of prices $\{r(t), w(t)\}$; such that: 
(i) the allocations received by the households solve their optimization problems, given prices;

(ii) the allocations received by the firms solve their optimization problems, given prices;

(iii) the government satisfies its budget constraints (17) - (19) and a feasibility constraint,

$$
\int_{-\infty}^{t} x(i, t) \lambda e^{-\lambda(t-i)} d i=X(t)
$$

(iv) all markets clear:

$$
\begin{gathered}
L(t)=1, \\
K(t)=A(t), \\
C(t)+\dot{K}(t)+G(t)+X(t)=Y(t)-\delta K(t) .
\end{gathered}
$$

Equations $(17)-(22)$ can be used to eliminate $L(t), X(t), G(t)$ and $A(t)$ from the production function (13), the law of motion for the interest rate (16), the propensity to consume (7) and the differential equations (12) and (23):

$$
\begin{aligned}
Y(t) & =B^{1 / \alpha} \tau_{G}^{(1-\alpha) / \alpha} K(t), \\
r(t) & =(1-\tau) \alpha B^{1 / \alpha} \tau_{G}^{(1-\alpha) / \alpha}-\delta=r, \\
\Delta(t)^{-1} & =\frac{1}{\sigma}[\lambda+\rho+(\sigma-1)(r+\lambda)]=\Delta^{-1}, \\
\dot{C}(t) & =\frac{1}{\sigma}[r-\rho] C(t)-\Delta^{-1} \lambda K(t), \\
\dot{K}(t) & =\left[(1-\tau) B^{1 / \alpha} \tau_{G}^{(1-\alpha) / \alpha}-\delta\right] K(t)-C(t) .
\end{aligned}
$$




\subsection{The Steady-State}

Denote the growth rate of the capital stock by $\gamma(t)$ and the consumption-capital ratio by $\bar{C}(t)$. Suppose that a steady-state exists in which aggregate consumption grows at the same rate as the capital stock. The locus of points that satisfy the steady-state condition and the law of motion for aggregate consumption (27) are given by:

$$
\frac{\dot{C}(t)}{C(t)}=\gamma(t)=\frac{1}{\sigma}(r-\rho)-\Delta^{-1} \lambda \bar{C}^{-1}
$$

This locus and the aggregate resource constraint are depicted in Figure 1.

Notice that there is a unique $C / K$ and $\gamma$ combination that satisfy the resource constraint, the law of motion for consumption and the steady-state restriction.

Figure 1: The Steady-State (Insert Figure 1 here - see last page)

The arrows in Figure 1 indicate how the growth rate of the capital stock and the consumption-capital ratio would change if the economy was not at the steady-state. For example, suppose the economy starts with a consumption-capital ratio less than the steady-state value. If this were the case the capital stock would grow faster, and consumption slower, than the steady-state growth rate. As a result, the consumption-capital ratio would fall over time and growth rate of the capital stock would increase. At some point the growth rate of the capital stock will reach a value large enough to violate the transversality condition (4). This violation of the transversality condition means that households are over saving: utility could be increased if 
consumption were increased at earlier dates. This implies that $\bar{C}(0)<\bar{C}^{*}$ cannot be an equilibrium.

Now suppose the economy starts with a consumption-capital ratio greater than the steady-state value. If this were the case the capital stock would grow slower, and consumption faster, than the steady-state growth rate. As a result, the consumption-capital ratio would rise over time; and the growth rate of the capital stock would fall over time, and would eventually become negative.

When the capital stock reaches zero; in order to satisfy the resource constraint, consumption must also jump down to zero at this time. However, this jump violates the Euler Equation (27), and therefore $\bar{C}(0)>\bar{C}^{*}$ cannot be an equilibrium.

These results leave us with $\bar{C}(0)=\bar{C}^{*}$ as the only possible equilibrium, which implies that there are no transitional dynamics in this model. The consumption and savings decisions of the agents put the economy immediately in the steady-state.

An increase in life expectancy, that is a fall in $\lambda$, would make the $\dot{C} / C=\gamma$ locus flatter. As $\lambda$ approaches zero, life expectancy approaches infinity, and the locus approaches a horizontal line at $\gamma(t)=(r-\rho) / \sigma$. As life expectancy increases, the propensity to save out of wealth $\left(1-\Delta^{-1}\right)$ rises; and this in turn leads to a higher aggregate savings rate and a higher aggregate growth rate. In the model, the propensity to save affects the long-run growth rate because the aggregate production function (24) is linear in capital, and therefore at the aggregate level capital does not have a diminishing marginal product. ${ }^{6}$ 


\section{Implications for Public Policy}

This section investigates the implications of the model for public policy. Figure 1 will be used to help identify the effects that taxes have on economic growth and social welfare, and the role that finite horizons plays in the determination of optimal tax policy. The economic implications of a change in the tax rate will be shown to depend on how the proceeds of the tax are allocated: (i) tax revenue could be used to finance utility enhancing services; or (ii) it could be used to finance public infrastructure.

Case (i): If the tax rate is increased and the proceeds are used to finance utility enhancing services (i.e. $\tau_{X}$ increases); then both the $\dot{C} / C=\gamma$ locus and the production function will shift down, resulting in a lower rate of economic

growth. The $\dot{C} / C=\gamma$ locus shifts down because the higher tax rate lowers the after-tax rate of return to capital, and therefore reduces the incentive to save and to invest. The production function shifts down because the higher tax rate reduces disposable output, and results in less goods available to be allocated to capital investment. Despite the fact that the services provided by government generate utility for the households, the financing of these services has adverse effects on the rate of economic growth.

Case (ii): Now suppose that the additional revenue raised by increasing the tax rate is used to finance public infrastructure (i.e. $\tau_{G}$ increases). Since public infrastructure is complementary to private capital, additional infrastructure raises the rate of return to capital and improves the production possibilities of the economy. In this case the $\dot{C} / C=\gamma$ locus and the 
production function both move in an ambiguous direction. The direction of movement for both curves depends on the sign of the following function:

$$
(1-\alpha)\left(1-\tau_{X}\right)-\tau_{G}
$$

If (30) is positive, then an increase in $\tau_{G}$ leads to an increase in both the after-tax rate of return to capital and disposable output. A rise in the after-tax rate of return to capital produces and upward shift of the $\dot{C} / C=\gamma$ locus, whereas a rise in disposable output produces an upward shift of the production function. As a result, the growth rate increases. On the other hand, if (30) is negative, then both curves shift down when $\tau_{G}$ rises, and growth slows. Figure 2 plots the Barro Curve, which shows the relationship between the expenditure share $\left(\tau_{G}=G / Y\right)$ and the aggregate growth rate.

Figure 2: The Barro Curve (Insert Figure 2 here - see last page)

The government can maximize growth by setting $\tau_{X}=0$ and $\tau=\tau_{G}=1-\alpha$. However, the growth maximizing income tax rate is not welfare maximizing. This is obvious from the utility function, which requires households to receive positive amounts of the utility enhancing service in order to generate utility. Suppose the objective of the government is to choose its tax and expenditure policies to solve the following optimization problem:

$$
\max _{\tau_{G}, \tau_{X}} U(t)=\int_{t}^{\infty} u[C(v), X(v)] e^{-(\rho+\lambda)(v-t)} d v
$$

subject to $(2),(24)-(28)$, and the steady-state restriction that $\dot{C}(t) / C(t)=\dot{K}(t) / K(t)=\gamma$. In order to facilitate a comparison of the results 
of this study with those of Barro (1990) and Mourmouras and Lee (1999), it is necessary to adopt the same objective function that they used. In their papers and this paper the government must choose the income tax rate to maximize the welfare of the representative (or average) household. In addition, in the current paper the government must also determine the optimal composition of its expenditures. ${ }^{7}$

As it turns out the value of $\tau_{G}$ that solves the government's optimization problem is equivalent to the value that maximizes growth, $\tau_{G}^{*}=1-\alpha$. This is also the value that maximizes social welfare in Barro's infinite horizon version of this model and in Mourmouras and Lee's finite horizon version with public infrastructure but no utility enhancing services. These similarities occur because the optimal policy rule arises out of the production externality effects associated with public infrastructure, and not out of the consumption externality effects associated with finite horizons or utility enhancing services.

Unfortunately, given the nonlinearity of the optimization problem, an expression relating the optimal value of $\tau_{X}$ to life expectancy is more difficult to derive from the first-order conditions. Instead the optimal value of $\tau_{X}$ will be determined by calibrating parameter values and then iterating on the utility function. Whenever possible parameter values will be borrowed from the relevant literature. Following Barro (1990), $\rho=0.02, \delta=0.10$ and $\alpha=0.75$. A value for capital's share parameter in this range is necessary to generate a realistic income tax rate. The probability of death $(\lambda)$ is set to 0.0133, and implies a life expectancy of 75 years. The micro evidence on the 
coefficient of relative risk aversion suggests that $\sigma$ is between 1 and 2 . As a compromise a value of 1.5 was selected. It is assumed that the government chooses its expenditure shares optimally; that is, to solve (31). As such, $\tau_{G}$ is set to 0.25 . The value of $\tau_{X}$ is set to 0.15 , and this implies an income tax rate $(\tau)$ of 40 percent. The share parameter in the utility function $(\beta)$ is set to 0.6391. For this value the expenditure share going to utility enhancing services $\left(\tau_{X}=0.15\right)$ is optimal. Finally, the technology parameter in the production function $(B)$ is set to 0.6512 . For this value the aggregate variables in the benchmark parameterization of the model grow at an annual rate of 2 percent.

Figure 3: Social Welfare Maximizing Expenditure Share, $\tau_{X}=X / Y$ (Insert Figure 3 here - see last page)

An analysis of the sensitivity of $\tau_{X}^{*}$ to life expectancy $(1 / \lambda)$ is depicted in Figure 3. Notice that if life expectancy deteriorates, then $\tau_{X}^{*}$ rises. In the model, the government determines the optimal value of $\tau_{X}$ by equating the marginal benefits of utility enhancing services to the marginal costs. The provision of utility enhancing services is costly in part because their production requires the use of the economy's scarce resources, and in part because these services are financed from a distortionary income tax system. An increase in $\tau_{X}$, for example, would reduces the after-tax rate of return to capital, and would lead to a fall in the propensity to save out of wealth and a fall in the growth rate. However, if an economy has a relatively low life expectancy, then the costs associated with slow grow are relatively low, and 
therefore the optimal value of $\tau_{X}$ will be relatively high.

\section{Conclusion}

In the model there are two channels through which an increase in life expectancy affects the rate of economic growth. First, a rise in life expectancy has a direct and positive effect on the propensity to save out of wealth; and since capital has a constant marginal product at the aggregate level, a higher propensity to save leads to a higher rate of growth. Second, life expectancy indirectly affects the propensity to save, and therefore the growth rate, through the tax system. For example, if life expectancy improves, then the costs associated with slow growth rise. As a result, the optimal policy action calls for the government to reduce the distortionary effects of taxation, by reducing the expenditure share for utility enhancing services, $\tau_{X}$. A fall in $\tau_{X}$ raises the after-tax rate of return to capital, which in turn raises the willingness to save and the growth rate.

The results of this paper demonstrate that in order to determine the full effect that life expectancy has on the rate of economic growth, it is also necessary to determine the effect that life expectancy has on the composition of government spending. Figure 4 shows the response of the aggregate growth rate to a change in life expectancy assuming: (i) the income tax rate is fixed, or (ii) the government changes the income tax rate optimally in response to a change in life expectancy. As indicated above, the growth rate is more 
sensitive to changes in life expectancy if the government follows an optimal tax policy rule.

Figure 4: The Relationship Between Life Expectancy and Growth Under Fixed and Optimal Tax Policies (Insert Figure 4 here - see last page) 


\section{Notes}

1. It is assumed that government expenditures enter the utility function as a flow, and not a stock. However, a valid augment could be made in favour of either specification. For example, government expenditures that are used to fund a symphony orchestra would represent a flow variable, because if the funding stopped then the orchestra would breakup and there would be no capital remaining. Another example of government spending on utility enhancing services is a public park. A park could be considered a stock or a flow variable. If the value of the land is the best determinant of the park's value to households, then it would be appropriate to enter the park as a stock variable. On the other hand, if it is the maintenance cost of the park that generates the utility, then it should enter as a flow.

2. The effect of having a positive probability of death is to increase the household's effective discount rate. This result was obtained by Yaari (1965).

3. In the endogenous growth literature government expenditures have entered the production function as both a flow [see, for example: Barro (1990), Turnovsky (1996), and Mourmouras and Lee (1999)] and a stock [see, for example: Futagami, Morita and Shibata (1993), and Turnovsky (1997)]. Although entering government infrastructure as a stock is arguably more plausible, it is the less common procedure. The 
introduction of infrastructure as a stock variable would generate transitional dynamics, which are not present in the model when infrastructure enters as a flow variable. These transitional dynamics would complicate the calculations and thus obscure the basic message of the paper - that the optimal income tax rate and the composition of government spending are sensitive to life expectancy.

4. There is a large amount of empirical literature which has found physical infrastructure to be an important determinant of economic growth. The articles most often cited are Aschauer (1989) and Easterly and Rebelo (1993). For a more recent study, see Canning (1999). For a review of the literature on the contribution of infrastructure to aggregate output and growth, see Gramlich (1994) or Poot (2000).

5. Although there is empirical evidence linking infrastructure expenditures to economic growth, these expenditures alone have not been found to be sufficient to generate endogenous growth. Ghosh and Mourmouras (2002) attempt to correct this problem in their model by introducing knowledge spillover effects from the capital stock à la Romer (1986). In their paper, both the spillover effects from the capital stock and public infrastructure expenditures combine to generate endogenous growth. The knowledge spillover effects from capital accumulation could be added to the current paper as well. However, the response of government to a change in life expectancy would be qualitatively the same with or without them, and therefore they have been left out. There is another good reason for not 
adding knowledge spillovers to the model. As it is specified now, the production side of the model is identical to the setup of the model in the Mourmouras and Lee (1999) paper. Therefore, the two papers can be compared to isolate the effects that utility enhancing government services have on the government's optimal tax and expenditure policy.

6. In the Neoclassical growth model the length of time that the propensity to save out of wealth affects the growth rate depends on how fast diminishing returns sets in. For a more detailed discussion of the dynamics of an economy with an aggregate production function that is linear in capital, see Barro and Sala-i-Martin (Chapter 4, 1995).

7. Calvo and Obstfeld (1988) also analyzed optimal fiscal policy in a model with finite lived heterogenous agents. However, in their paper the private consumption good enters as the only argument in the utility function. They solved a planning problem of optimally allocating consumption over time and optimally distributing consumption at each moment among those alive. In comparison, in the current paper, the government must decide on its fiscal policy taking as given the market distribution of the private consumption good. 


\section{References}

Aschauer, D.A. (Mar. 1989). Is public expenditure productive?. Journal of Monetary Economics 23(2): 177-200.

Barro, R.J. (1997). Determinants of Economic Growth. Cambridge, MA: MIT Press.

Barro, R.J. (Oct. 1990). Government spending in a simple model of endogenous growth. Journal of Political Economy 98(5): S103-S125.

Barro, R.J., and Sala-i-Martin, X. (1995). Economic Growth. New York: McGraw-Hill.

Bhargava, A., Jamison, D.T., Lau, L.J., and Murray, C.J.L. (May 2001). Modeling the effects of health on economic growth. Journal of Health Economics 20(3): 423-440.

Blanchard, O.J. (Apr. 1985). Debt, deficits, and finite horizons. Journal of Political Economy 93(2): 223-247.

Bruce, N., and Turnovsky, S.J. (May 1999). Budget balance, welfare, and the growth rate: "dynamic scoring" of the long-run government budget. Journal of Money, Credit, and Banking 31(2): 162-186.

Calvo, G.A., and Obstfeld, M. (Mar. 1988). Optimal time-consistent fiscal policy with finite lifetimes. Econometrica 56(2): 411-432.

Canning, D. (Nov. 1999). Infrastructure's contribution to aggregate output. World Bank Policy Research Working Paper No. 2246. 
Easterly, W., and Rebelo, S. (Dec. 1993). Fiscal policy and economic growth: an empirical investigation. Journal of Monetary Economics 32(3): 417-458.

Futagami, K., Morita, Y., and Shibata, A. (Dec. 1993). Dynamic analysis of an endogenous growth model with public capital. Scandinavian Journal of Economics 95(4): 607-625.

Ghosh, S., and Mourmouras, I.A. (Jan. 2002). On public investment, long-run growth, and the real exchange rate. Oxford Economic Papers 54(1): 72-90.

Gramlich, E.M. (1994). Infrastructure investment: a review essay. Journal of Economic Literature XXXII: 1176-96.

Heijdra, B.J., and Ligthart, J.E. (2002). Tax policy, the macroeconomy, and intergenerational distribution. IMF Staff Papers 49(1): 106-127.

Mourmouras, I.A., and Lee, J.E. (Sept. 1999). Government spending on infrastructure in an endogenous growth model with finite horizons. Journal of Economics and Business 51(5): 395-407.

Kalemli-Ozcan, S., Ryder, H.E., and Weil, D.N. (June 2000). Mortality decline, human capital investment, and economic growth. Journal of Development Economics 62(1): 1-23.

Poot, J. (Fall 2000). A synthesis of empirical research on the impact of government on long-run growth. Growth and Change 31: 516-546. 
Rebelo, S. (June 1991). Long-run policy analysis and long-run growth. Journal of Political Economy 99(3): 500-521.

Reinhart, V.R. (Mar. 1999). Death and taxes: their implications for endogenous growth. Economics Letters 62(3): 339-345.

Romer, P.M. (Oct. 1986). Increasing returns and long-run growth. Journal of Political Economy 94(5): 1002-1037.

Turnovsky, S.J. (Sept. 1997). Fiscal policy in a growing economy with public capital. Macroeconomic Dynamics 1(3): 615-639.

Turnovsky, S.J. (Apr. 1996). Optimal tax, debt, and expenditure policies in a growing economy. Journal of Public Economics 60(1): 21-44.

Turnovsky, S.J., and Fisher, W.J. (May 1995). The composition of government expenditure and its consequences for macroeconomic performance. Journal of Economic Dynamics and Control 19(4): $747-786$.

Yaari, M.E. (1965) Uncertain lifetime, life insurance, and the theory of the consumer. Review of Economic Studies 32: 137-150. 


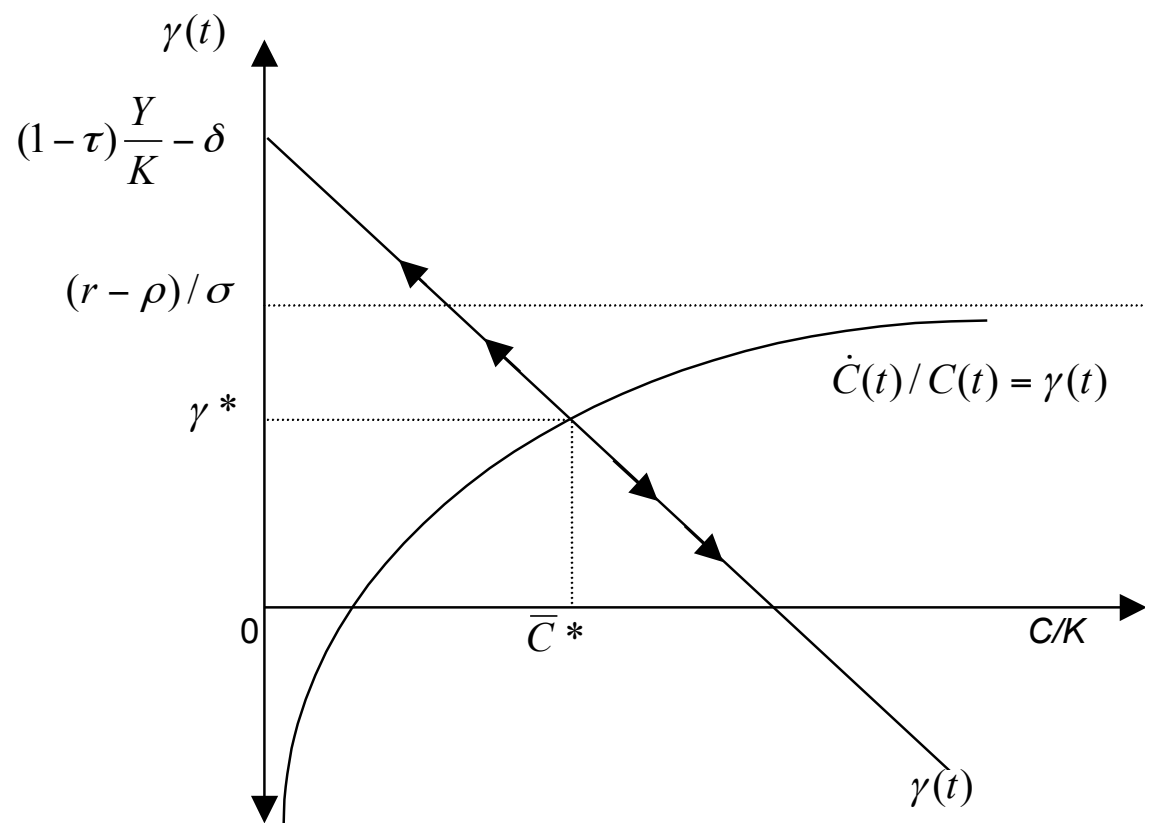

Figure 1: The Steady-State 


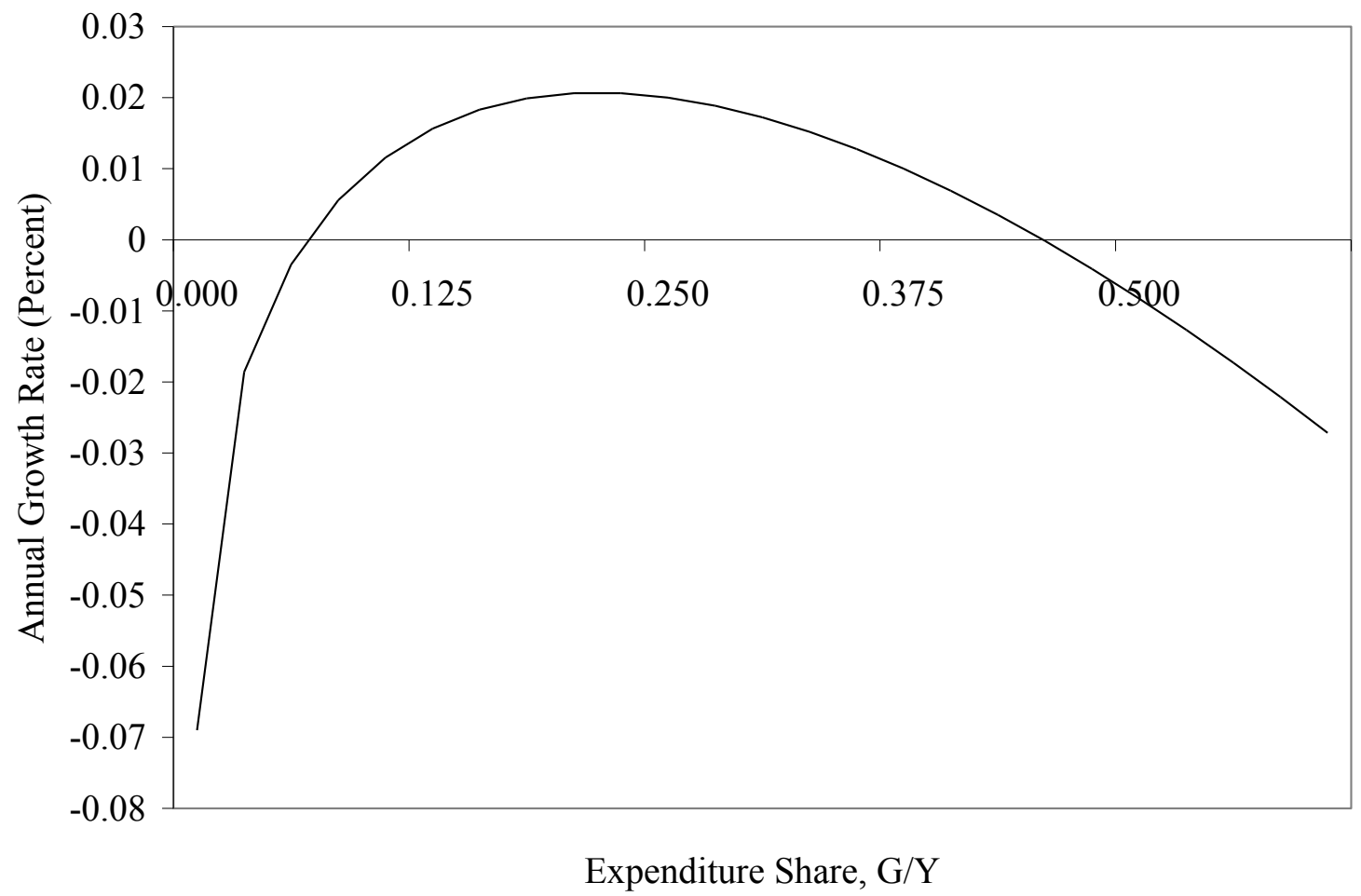

Figure 2: The Barro Curve. Parameter values are: $\rho=0.02, \lambda=0.0133, \sigma=1.5$, $\beta=0.6391, \delta=0.1, \alpha=0.75, B=0.6512$ and $\tau_{X}=0.15$. 


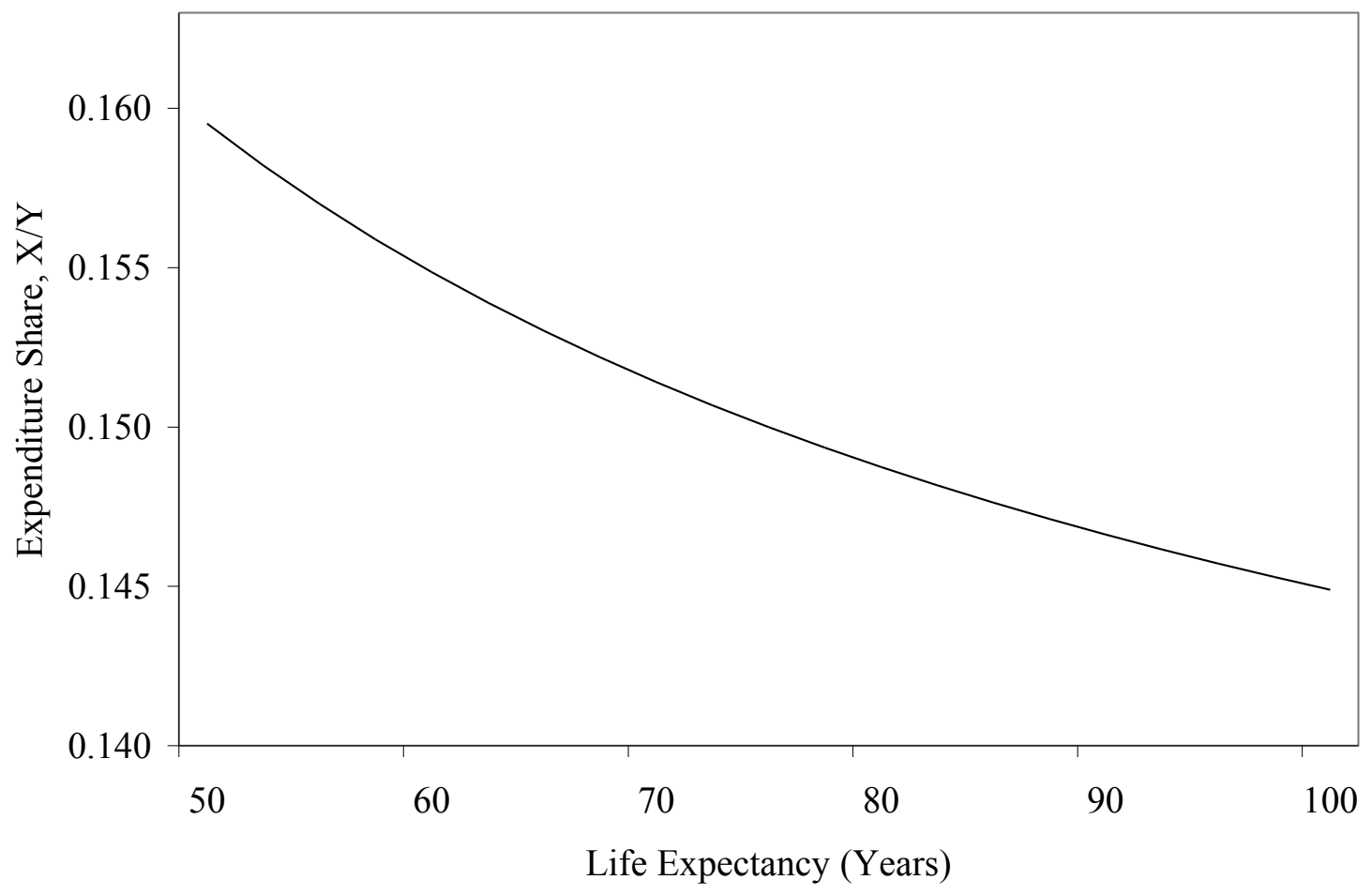

Figure 3: Social Welfare Maximizing Expenditure Share, $\tau_{X}=X / Y$ 


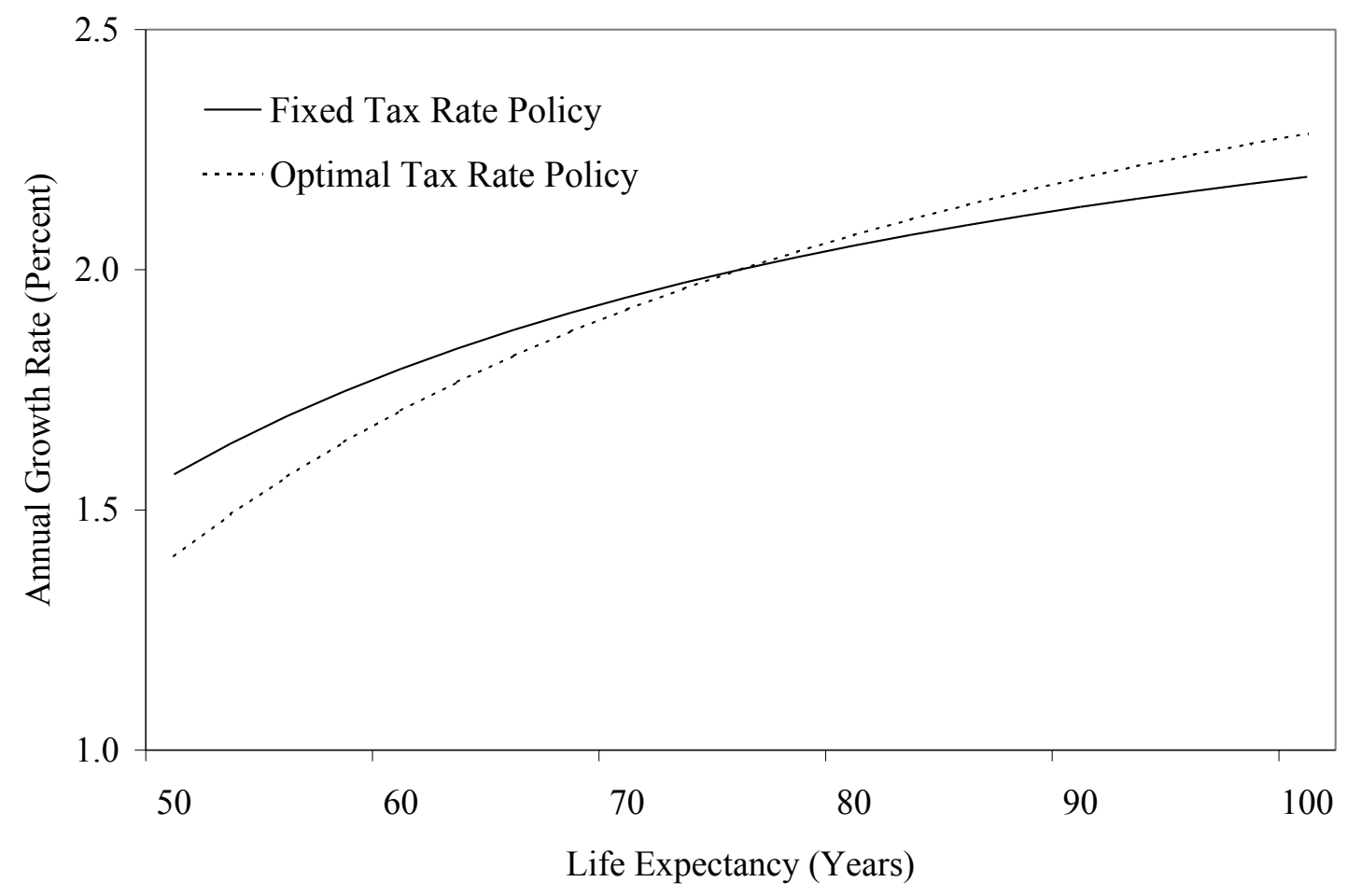

Figure 4: The Relationship Between Life Expectancy and Growth Under Fixed and Optimal Tax Policies 